\title{
A Current-Awareness Service for Faculty and Staff: The Stout Experience
}

\author{
John J. Jax and Van C. Houlson
}

This report describes a prototype current-awareness service for faculty and staff at the University of Wisconsin-Stout. The service involved selective dissemination of information using online bibliographic databases and the routing of table of contents from selected periodical holdings. The project resulted in delivery of more than 3,000 publications from references in thirty-eight databases and from the tables of contents of 154 periodical titles. Document evaluations and survey results show the patterns of use among faculty, the types of documents selected, the pattern of delivery, and the effectiveness of databases and tables of contents in providing current awareness.

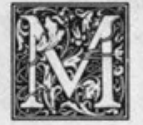

any disciplines in scientific and technical fields require that the latest information be available to researchers, faculty, students, and other library users. Too much is published and too little time is available to review all current information. Particularly for university and college personnel, a serious deficiency can result when time and resources restrict keeping abreast of new publications. At the University of Wisconsin-Stout, a current-awareness service combined with document delivery was developed to assist faculty and staff in their efforts to read the newest, most relevant information in their fields.

During periods of little or no budget increases, a new library service requires both the allocation of existing resources and additional start-up funds. The project was successfully funded through a matching grant proposal to the Stout Foundation, from August 1985 to January 1986. The service included SDI (selective dis- semination of information) from commercially available databases, the routing of tables of contents from selected periodicals held by the library, and document delivery for any publication identified from either source.

UW-Stout has strong programs in the applied sciences, vocational and technical education, home economics, hospitality, and counseling and other psychological services. Many faculty volunteered in response to the campuswide publicity sent out, and thirty-three participants were selected to represent a cross section of academic disciplines. Current-awareness profiles were designed in the applied and social sciences including robotics, actuarial science, telecommunications, international business, nutrition, family violence, correctional education, vocational rehabilitation, and tourism. Participants represented the major divisions on campus: the School of Industry and Technology, the School of Home Economics, the School of

John J. Jax is director of the Library Learning Center, and Van C. Houlson is Computer-Assisted Reference Librarian at the University of Wisconsin-Stout, Menomonie, Wisconsin 54751. 
Education and Human Services, the School of Liberal Studies, and a group of "others." This last group had faculty and staff from support services such as the library, the counseling center, student personnel, and administration.

\section{REVIEW OF LITERATURE}

There are many references to SDI and current-awareness information services in the literature. However, relatively few documents offer direct applications to broad-based higher education experiences. Charles Bourne reported that the University of California system implemented a combination SDI and document delivery system for nine campuses in 1974. ${ }^{1}$ A small prototype SDI system (nine faculty) was also initiated at the University of Arkansas-Little Rock in 1974-75. ${ }^{2}$ The University of Bath (United Kingdom) produced a highly rated current-awareness system with a personalized information service for academic researchers at the Universities of Bath and Bristol in 1969-71. ${ }^{3}$ The University of Natal (South Africa) developed a prototype SDI service (1980-84) that successfully updated academic researchers whose interests spanned a wide interdisciplinary range. ${ }^{4}$ The most useful reports for purposes of implementing a successful automatic current-awareness service at UW-Stout proved to be the Poncelet guide developed for the UNESCO projects in developing countries in $1980^{5}$ and the UNESCO-sponsored SDI project conducted at the University of Sains, Malaysia in $1983 .^{6}$

\section{GOALS/OBJECTIVES}

The goals of providing this service were threefold:

1. Establish an efficient, cost-effective current-awareness service.

2 . Enable faculty to become better informed in their fields.

3. Facilitate research.

Specific objectives were formulated to create a quality current-awareness service. They can be summarized as:

1. Provide faculty with access to comprehensive sources of current, relevant, specialized information.
2. Facilitate ways in which faculty can save time, effort, and funds in reviewing and obtaining publications in their fields.

3. Provide on a regular basis information that is more current than that routinely found by faculty.

The project also investigated the direct impact of a current-awareness service on faculty and staff. The following objectives were developed to examine the research aspects of this service in the university environment:

1. Determine how faculty and staff obtain current information in their fields.

2. Identify current information gaps that can be eliminated through provision of current-awareness services.

3 . Contribute to qualitative improvements in faculty instruction and research.

4. Increase the quantity of relevant current information scanned by faculty in keeping abreast of their fields.

There were other outcomes that were important to evaluate as well. How would faculty and staff value the service, and at what level would they support it fiscally? What gaps in the collection could be identified where collection development could be applied? Would the SDI service combined with document delivery be a costeffective alternative to enlarging the periodical holdings? Also of interest were those bibliographic databases and periodical titles most relevant for the represented disciplines.

\section{ESTABLISHMENT OF PROFILES}

Thirty-three persons were chosen for the service and were interviewed by the project directors to provide insights into where informational gaps occurred. Other than attending professional conferences, faculty tended to rely heavily on a small core of journals and magazines to stay current in their fields. SDI profiles were explained and useful databases were selected. Topics were clarified by using a search request form that urged faculty to provide a narrative description, any known publications, and search terms from a thesaurus or index.

Search strategies were run on specific databases, and the results were reviewed by participants to determine the scope of 
their profiles. The strategies making up the profiles were modified as needed and finally established online. A second interview approximately one month later reviewed and refined the profiles. Search results were continuously monitored to improve the SDI profiles.

The thirty-one persons who became users of the service had a total of seventynine profiles designed in twenty different databases, with an average of 2.3 profiles per participant. Two other faculty members did not find the service useful and dropped out after a trial period. Online searches were also performed in eighteen other databases that did not have the automatic SDI feature, but which were of particular interest to some faculty. The number of search terms averaged 12.5 per profile, although there were extremes from three to fifty-three terms. The search logic and number of terms varied in relation to the complexity of the strategy and the scope of the profiles.

Participants also met with a librarian to select no more than five periodical titles from the collection for the tables of contents routings. A visit to the periodical collection assisted faculty in the selection process and was an opportunity for them to review the titles received, some of which were previously unknown. A subject analysis of known titles usually generated other pertinent titles. A total of 154 periodical titles were finally selected for routing photocopies from the tables of contents on a regular basis.

\section{"The SDIs required more effort be- cause they were complex to establish and because the participants were generally unfamiliar with online bib- liographic indexes."}

As part of the service, participants also agreed to complete a brief evaluation form that accompanied each delivered document. Besides rating each publication delivered for relevancy, the evaluation form allowed library staff to collect other data such as how the request originated, the type of document, and the source of delivery.

Setting up the current-awareness service for the table of contents routings was readily achieved. The SDIs required more effort because they were complex to establish and because the participants were generally unfamiliar with online bibliographic indexes. Participants frequently wanted multiple topics searched and limiting the current-awareness profile to a reasonable scope was not always clearly understood. For some of the profiles, creating an effective SDI in a database required continuous modification and refining.

\section{RESULTS OF THE SERVICE}

Over a period of thirteen months, 120 online searches and 556 SDI updates were sent to faculty and staff, representing over 12,000 bibliographic references. Also sent were 1,166 tables of contents. Each participant averaged twenty-two database search updates and thirty-seven table of contents routings. From these, a total of 2,233 requests for publications cited in the database updates and 906 requests for articles from the tables of contents were received from all participants. An average of ninety-seven publications was delivered to each participant during the project.

The School of Home Economics led all other groups in requesting and receiving publications. Their subject interests were well matched to the available SDI databases and periodicals used for the tables of contents routings. Disciplines in this group include early childhood education, clothing and textiles, food science and nutrition, and home economics administration. Participants from the School of Industry and Technology had the greatest per person average of citations and tables of contents routed to them. Topics from this school represented rapidly developing areas of research.

Different demands were placed on the library in achieving a 97 percent fill rate for all requested material. The 906 articles from the tables of contents routings were readily photocopied from the library collection, with few exceptions. Of the requests from database citations, periodical 
TABLE 1

SUMMARY STATISTICS

\begin{tabular}{|c|c|c|c|c|c|c|}
\hline & $\begin{array}{c}\text { Industry } \\
\& \\
\text { Technology }\end{array}$ & $\begin{array}{c}\text { Home } \\
\text { Economics }\end{array}$ & $\begin{array}{l}\text { Education } \\
\& \text { Human } \\
\text { Services }\end{array}$ & $\begin{array}{l}\text { Liberal } \\
\text { Studies }\end{array}$ & Others & Total \\
\hline Number of participants & 9 & 8 & 4 & 4 & 6 & 31 \\
\hline $\begin{array}{l}\text { ROUTED } \\
\text { Database citations } \\
\text { Table of contents }\end{array}$ & $\begin{array}{r}4,358 \\
410\end{array}$ & $\begin{array}{r}2,963 \\
318\end{array}$ & $\begin{array}{r}1,845 \\
116\end{array}$ & $\begin{array}{r}1,406 \\
107\end{array}$ & $\begin{array}{r}1,722 \\
215\end{array}$ & $\begin{array}{r}12,294 \\
1,166\end{array}$ \\
\hline $\begin{array}{l}\text { REQUESTED } \\
\text { Database citations } \\
\text { Table of contents } \\
\text { Total }\end{array}$ & $\begin{array}{l}630 \\
199 \\
829\end{array}$ & $\begin{array}{r}783 \\
398 \\
1,181\end{array}$ & $\begin{array}{r}271 \\
\quad 72 \\
343\end{array}$ & $\begin{array}{r}343 \\
78 \\
421\end{array}$ & $\begin{array}{l}206 \\
159 \\
365\end{array}$ & $\begin{array}{r}2,233 \\
906 \\
3,139\end{array}$ \\
\hline $\begin{array}{l}\text { DOCUMENTS DELIVERED } \\
\text { UW-Stout Library } \\
\text { Interlibrary Loan } \\
\text { Online and UMI }\end{array}$ & $\begin{array}{r}456 \\
339 \\
4 \\
\end{array}$ & $\begin{array}{r}709 \\
418 \\
1 \\
\end{array}$ & $\begin{array}{r}209 \\
120 \\
0 \\
\end{array}$ & $\begin{array}{r}201 \\
210 \\
0 \\
\end{array}$ & $\begin{array}{r}257 \\
95 \\
2 \\
\end{array}$ & $\begin{array}{r}1,832 \\
1,182 \\
7 \\
\end{array}$ \\
\hline $\begin{array}{l}\text { Total } \\
\text { Average } \\
\text { Duplicate requests } \\
\text { Unfilled } \\
\end{array}$ & $\begin{array}{r}799 \\
89 \\
4 \\
26\end{array}$ & $\begin{array}{r}1,128 \\
141 \\
13 \\
38 \\
\end{array}$ & $\begin{array}{r}329 \\
82 \\
0 \\
14\end{array}$ & $\begin{array}{r}411 \\
103 \\
1 \\
9 \\
\end{array}$ & $\begin{array}{r}354 \\
59 \\
4 \\
8\end{array}$ & $\begin{array}{r}3,021 \\
97 \\
23 \\
95 \\
\end{array}$ \\
\hline
\end{tabular}

TABLE 2

MEAN RATINGS FOR DOCUMENT EVALUATIONS

\begin{tabular}{lcccc}
\hline \hline & \multicolumn{2}{c}{$\begin{array}{c}\text { Databases } \\
(N=1758)\end{array}$} & \multicolumn{2}{c}{$\begin{array}{c}\text { Table of Contents } \\
(N=745)\end{array}$} \\
\hline Relevancy of document to profile & 3.9 & $(\mathrm{~S}=1.2)$ & 4.1 & $(\mathrm{~S}=1.1)$ \\
Level of new information & 3.7 & $(\mathrm{~S}=1.1)$ & 4.0 & $(\mathrm{~S}=1.1)$ \\
Overall quality of document & 3.7 & $(\mathrm{~S}=1.1)$ & 4.1 & $(\mathrm{~S}=1.0)$ \\
Estimated document usefulness & 3.6 & $(\mathrm{~S}=1.2)$ & 4.0 & $(\mathrm{~S}=1.1)$ \\
\hline
\end{tabular}

(Scale $=0-5: 0=$ not at all; $3=$ some; $5=$ very much)

Excludes May 1987 reshelving of 1,458 government documents separately reported

literature accounted for 89 percent of the publications, 8 percent were reports, and 3 percent were books and conference proceedings. Interlibrary loan was an important source of document delivery, filling more than 55 percent of the requests originating from database citations.

\section{DOCUMENT EVALUATIONS}

The evaluation forms sent out with every publication resulted in 2,503 evaluations, an 85 percent return rate. Publications were rated using four categories and a five-point scale. The ratings attempted to establish a value-with zero representing "no value," one as "low," three as "medium," and five as "high" - for each of the following:

1. Relevancy of the document to the profile;

2. Level of new information;

3. Overall quality of the document;
4. Estimated usefulness.

In addition to rating four categories for each publication, the evaluation forms were also coded to trace other information. Before the evaluations were sent out, the original reference was attached and the form was coded to trace either the database name or periodical title (of the table of contents), the delivery system used, the type of publication, and the ISSN if the publication was from a periodical.

The evaluations originating from the databases used for the SDI profiles totaled 1,758 forms, roughly 70 percent. Evaluations for those originating from tables of contents totaled 745 forms. The mean ratings are shown below for those from databases, those from the tables of contents, and all the evaluations.

The ratings for all categories are well within medium to high values. The mean ratings for publications from the tables of 
contents are higher than those from the databases, indicating a high degree of success by participants in selecting a variety of articles they considered relevant and useful.

Tables of contents appeared to be a familiar way to request documents and represented those periodical titles of most interest to participants. The document evaluations traced 105 periodicals originating from the tables of contents with a mean of 7.1 requests per title. Out of a total of 787 periodical titles identified from the evaluation forms, 82 percent originated from database citations. The database citations represented a much greater spread of titles with a mean of 1.9 requests per title.

A core group of periodical titles emerged from the evaluations. Titles having high request rates from the tables of contents were also the most frequently requested from database citations. While such a core indicates the significance of particular titles, the statistics show the number of periodicals of interest to a relatively small group of faculty and staff.

\section{EVALUATING SDI OUTPUT}

The precision ratio, or relevance ratio, is described by F. W. Lancaster as one method of evaluating the quality of a literature search. ${ }^{7}$ It represents the number of citations that are relevant out of the total number retrieved, and can be expressed as a percentage using the formula:

number of relevant documents retrieved

precision ratio $=$ total number of documents retrieved $\times 100$

For this project, there is no way of knowing the exact number of relevant documents actually retrieved from each database. Participants did select those of interest and later returned evaluations for many of those documents, but identifying a total number of only relevant documents remains elusive.

Another measure of quality in evaluating literature searches is recall, the extent to which a search strategy retrieves the total number of relevant citations that exists in a particular collection. ${ }^{8}$ For a database search, the recall ratio is the total number of relevant documents retrieved divided by the total number of relevant documents that are ultimately stored in the database. The recall ratio, a theoretical calculation, is not known for this project, but is a useful concept for discussing the output generated by the SDI profiles.

Detailed statistics were collected for the citations generated by the SDI profiles and those selected by participants for document delivery. These statistics can be used to measure the level of selection by participants in particular databases. A request ratio was devised to estimate the effectiveness of these profiles in generating relevant documents. For this study, the request ratio is expressed as the percentage of documents requested from the total number of database citations routed to participants. For the entire project, the percent requested from the database citations is calculated as follows:

$\%$ requested $=\begin{aligned} & \text { total database citations re- } \\ & \text { quested } \\ & \text { total database citations re- } \\ & \text { trieved } \times 100\end{aligned}$
$\%$ requested $=$
$\frac{2233}{12294} \times 100=18 \%$

The 18 percent request rate suggests a low precision ratio. Many of the SDI profiles were designed to maximize recall for updates to the databases. Other factors that influenced the amount retrieved by the SDI profiles included the scope and number of terms used to search the topic, the complexity of translating the topic into search terms, and the coverage of the databases for a given topic.

\section{SDI Request Activity by School}

The percentage of database citations from which documents were requested was compared among participants from the different schools at the University of Wisconsin-Stout. Below is the request ratio expressed as a percentage for each school.

Although individuals from Liberal Studies and Home Economics tended to use the service more than participants from other academic disciplines differ- 
TABLE 3

REQUESTS BY UNIVERSITY SCHOOL

\begin{tabular}{lc}
\hline \hline School & $\begin{array}{c}\text { Percent } \\
\text { Requested }\end{array}$ \\
\hline Liberal Studies & 24.6 \\
Home Economics & 23.9 \\
Education and Human Services & 14.6 \\
Industry and Technology & 14.3 \\
Others & 11.6 \\
\hline
\end{tabular}

ences were not determined. The participants from each school had profiles representing a mixture of scientific, technical, and social science interests.

\section{SDI Request Activity by Database}

From the document evaluations, 74 percent of the citations were traced to only five of the thirty-two different database files. Below is the request ratio expressed as a percentage by database:

The scientific and social science databases served more specialized interests. This included Scisearch, Mathfile, COMPENDEX, BIOSIS Previews, CAB Abstracts, $P A I S, N A R I C$, and Magazine Index.

The ratings from the document evaluations were also compiled for each database. The results show averages that conform to the ratings compiled for all evaluations originating from database citations, with the exception of PsycInfo and Social Scisearch. PsycInfo had a modest request rate of 16 percent, but a very high rating of 4.5 for "relevancy." Social Scisearch had the highest request rate but only a 3.4 rating for "relevancy" as well as the lowest ratings for all other categories. This could be explained by the lack of abstracts and descriptors in the citations from Social Scisearch, which is an impor- tant factor in selecting relevant documents. This contrast also highlights the limitation of using the percentage of requests to measure the effectiveness of the SDI profiles.

\section{SURVEY OF PARTICIPANTS}

At the end of the project a survey was sent to participants to evaluate the impact, effectiveness, and general usefulness of the service. Twenty-seven participants returned the survey. Roughly half of the questions were designed to measure levels of agreement using a five-point scale that ranged from one as "not at all," to three as "some," to five as "very much." Table 5 represents the mean ratings for responses to this part of the survey.

The responses show that the service was effective in broadening the quality and quantity of publications reviewed by participants in their specialized fields. Faculty also appeared to have spent more time reading, and less time doing literature searches, which was an important objective of this service. Document delivery was highly valued, no doubt because it saved time and made it extremely convenient to request publications. The ratings for "exhaustiveness" and "expectations" on the survey also reflect the ratings for

TABLE 4

REQUESTS BY DATABASES

\begin{tabular}{lc}
\hline \hline Database & $\begin{array}{c}\text { Percent } \\
\text { Requested }\end{array}$ \\
\hline Social Scisearch & 35 \\
ABI-INFO & 19 \\
Trade and industry Index & 18 \\
PsychInfo & 16 \\
ERIC & 12 \\
Thirteen other technical and scientific & 13 \\
Fourteen other social science & 13 \\
\hline
\end{tabular}


TABLE 5

EVALUATIONS OF SERVICE

Survey Statement

Mean Rating

"Document delivery through campus mail was useful"

"Established profile and databse citations met expectations"

"Tables of contents were useful"

"Better informed because of participating in SDI"

4.23

"Project increased awareness of publications in field"

3.96

"Citations received were exhaustive of subject field"

"Spent more time reading in field"

"Saved considerable amount of research time"

"Useful for research and classroom"

Improvements in instruction or research were realized"

3.20

Survey Results $(\mathrm{N}=27)$ and Mean Ratings $($ Scale $=1-5)$

TABLE 6

SURVEY QUESTIONS ON IMPACTS OF SERVICES

\begin{tabular}{|c|c|c|}
\hline \multicolumn{3}{|l|}{ "Estimated hours per month saved" } \\
\hline \multirow{3}{*}{\multicolumn{3}{|c|}{$\begin{array}{l}\text { "Percent of materials read that produced new research or teaching leads" } \\
18 \% 1-10 \text { percent } 41 \% 11-15 \text { percent } \\
\text { "Prior to service . . . experience difficulty identifying articles in field percent } \\
42 \% \text { Yes } 58 \% \text { No } \\
\text { "Percent periodical citations directly useful to work" }\end{array}$}} \\
\hline & & \\
\hline & & \\
\hline $58 \%$ directly useful $18 \%$ useful but not necessary & $13 \%$ already aware & $6 \%$ not useful \\
\hline \multicolumn{3}{|l|}{ "Suggest new titles for library acquisition" } \\
\hline \multicolumn{3}{|l|}{$\begin{array}{l}48 \% \text { Yes } \\
\text { "Database citations shared with others" }\end{array}$} \\
\hline $\begin{array}{l}41 \% \text { routed in department } 37 \% \text { with } 3-5 \text { persons } \\
\text { "Total number of citations received" }\end{array}$ & $7 \%$ with 1-2 people & $11 \%$ not shared \\
\hline $66 \%$ too many $19 \%$ satisfactory & $15 \%$ too few & \\
\hline $\begin{array}{l}\text { "Insufficient databases in field" } \\
11 \% \text { Yes } \\
89 \% \text { No }\end{array}$ & & \\
\hline
\end{tabular}

"level of new information" and "relevancy" on the document evaluations in table 3 .

The survey also included questions designed to quantify the impact and outcome of the service. Table 6 shows the responses to these questions about the service.

The responses in table 6 show the impact of the service on the faculty and staff. Almost all participants indicated saving at least six hours per month, and more than half of them estimated savings greater than ten hours per month. The number of database citations estimated as "directly useful" was high and 82 percent of the participants estimated that more than 10 percent of the delivered documents were applied to their research or teaching activities. The SDI updates also reached col- leagues not directly participating in the project as indicated by the participants $(89$ percent) who shared their database citations with others.

Participants showed a concern for the number of citations generated by the SDI profiles: 66 percent indicated that too many citations were received. Profiles were designed to maximize the recall of pertinent literature, but some users may not have valued this as much as precision, particularly among those profiles containing two or more topics.

\section{COST ANALYSIS}

The direct costs included online connect time, offline SDI charges, interlibrary loan fees, and photocopying costs. SDI and document delivery costs for the thirteen months of service are shown in table 7. 
TABLE 7

DIRECT COSTS

\begin{tabular}{lr}
\hline \hline Online costs ( 300 sessions) & $\$ 2,400$ \\
SDI fees (556 updates) & $\$ 4,280$ \\
Total online vendor costs & $\$ 6,680$ \\
Interlibrary loan and UMI fees (1,188 requests) & $\$ 6,170$ \\
Photocopying ( 3,000 pages at .03) & $\$ 90$ \\
Total document costs & $\$ 6,260$ \\
\hline
\end{tabular}

Online search costs included 120 preliminary searches and 179 sessions to input and edit the seventy-nine SDI profiles. The costs for each SDI update varied depending on the number of citations printed and averaged $\$ 17$ per month for each participant. Online costs and staff time were also incurred to create and maintain the SDI profiles. The time spent on each SDI averaged five hours per profile, although some hours were required to refine.

The greatest costs appeared to be in providing document delivery. Interlibrary loan was a major cost because it involved both direct fees and staff time. The interlibrary loan staff experienced a 30 percent increase in its workload. Delivering documents from in-house sources also proved to be labor intensive. Locating, photocopying, and delivering publications required ten hours per week from supervisory staff and seventeen hours per week from students assistants.

\section{CONCLUSION}

The statistics and evaluations show the success with which this currentawareness service was developed for faculty and staff. Access to comprehensive and current sources of information increased the quality and quantity of literature read by faculty, saved faculty an enor- mous amount of time in locating and obtaining publications, and made a significant impact on faculty research and training.

Survey responses indicated 42 percent of the participants experienced difficulty identifying literature prior to the service. The high ratings for "exhaustiveness" and the quantity of publications delivered suggest that many of the problems in locating information were solved by the service. Additional comments expressed overwhelming approval and satisfaction with the entire service, and support for continuation through reallocations from the university budget.

Strengths and weaknesses in the library's collections were also identified, and titles were added to improve the coverage in certain fields. While the cost of a current-awareness and documentdelivery service is significant, the quantity of publications used directly must be considered against the expense of maintaining large periodical collections that are seldom used by faculty. The results of this project strongly suggest that currentawareness services are appropriate for academic libraries and have a positive impact on the professional development, scholarly research, and teaching activities of faculty and staff.

\section{REFERENCES}

1. Charles P. Bourne, "Improvements in the Coupling of SDI System Output with Document Delivery Systems," Journal of Chemical Information and Computer Sciences, 16, no.1:27-30 (1976).

2. Steve Parker and Rathy Essary, "A Manual SDI System for Academic Libraries," Reference Quarterly, 15:47-54 (Fall 1975).

3. Susan M. Evans and Maurice B. Line, "A Personalized Service to Academic Researchers: The Ex- 
perimental Information Service in the Social Sciences at the University of Bath, Journal of Librarianship, 5, no.3:214-32 (July 1973).

4. C. Merret, "SDI in an Academic Community," South African Journal of Library and Information Science, 53:200-2, (Dec. 1985).

5. J. Poncelet, "Guide for Establishment and Evaluation of Services for Selective Dissemination of Information" (Paris, France: UNESCO, ERIC Document Reproduction Service, ED 205 174, 1980).

6. Coudert-Schkbowski, The Evaluation of Sismakom, Computerized SDI Project, Universiti of Sains Malaysia (Paris: UNESCO, 1983).

7. F. W. Lancaster, Information Retrieval Systems: Characteristics, Testing, and Evaluation, $2 \mathrm{~d}$ ed. (New York: Wiley, 1979), p.111-17.

8. Ibid.

\section{STATEMENT OF OWNERSHIP AND MANAGEMENT}

College \& Research Libraries is published bi-monthly by the American Library Association, 50 E. Huron St., Chicago, IL 60611 . Annual subscription price, \$17.50. American Library Association, owner; Charles Martell, editor. Second-class postage paid at Chicago, Illinois. Printed in U.S.A. As a nonprofit organization authorized to mail at special rates (Section 423.12 , Domestic Mail Manual), the purpose, function, and nonprofit status of this organization and the exempt status for federal income tax purposes have not changed during the preceding twelve months.

\section{EXTENT AND NATURE OF CIRCULATION}

("Average" figures denote the average number of copies printed each issue during the preceding twelve months; "Actual" figures denote actual number of copies of single issue published nearest to filing date-the July 1988 issue.) Total number of copies printed: Average, 13,525; Actual, 13,521. Paid and/or requested circulation: not applicable (i.e., no sales through dealers and carriers, street vendors and counter sales). Mail subscriptions: Average, 11,806; Actual, 11,706. Total paid and/or requested circulation: Average, 11,806; Actual, 11,706. Free distribution by mail, carrier or other means, samples, complimentary, and other free copies: Average, 181; Actual, 130. Total distribution: Average, 11,987; Actual, 11,836. Copies not distributed: office use, left over, unaccounted, spoiled after printing: Average, 1,538; Actual, 1,685. Returns from news agents: not applicable. Total (sum previous three entries): Average, 13,525; Actual, 13,521.

Statement of Ownership, Management and Circulation (PS form 3526, Dec. 1985) for 1988 filed with the United States Post Office Postmaster in Chicago, September 30, 1988. 